\title{
DYNAMIC LIGHT SCATTERING BY NANO- AND MICRO-SIZED COMPLEXES IN THE SYSTEM $\mathrm{K}_{2}$ REBR $_{6} / \mathrm{P}$-AMINOBENZOIC $\mathrm{ACID} / \mathrm{HBR} / \mathrm{H}_{2} \mathrm{O}$
}

S.N.Osmanova ${ }^{1}$, U.A.Kerimova ${ }^{1}$, N.S.Osmanov ${ }^{1}$, E.H.Ismailov², S.A.Suleymanova ${ }^{2}$. ${ }^{1}$ Institute of Catalysis and Inorganic Chemistry named after acad. M.F.Nagiyev of Azerbaijan National Academy of Sciences.

113, H. Javid Ave., Baku - AZ1143, Azerbaijan.

e-mail: o.sevinc1985@rambler.ru

${ }^{2}$ Institute of Petrochemical Processes named after acad. Yu.G.Mamedaliyev of Azerbaijan National Academy of Sciences.

30, Khojali pr., Baku- AZ1025, Azerbaijan.

e-mail: etibar.ismailov@gmail.com

\section{ABSTRACT}

$\mathrm{K}_{2} \mathrm{ReBr}_{6} / \mathrm{p}$-aminobenzoic acid/ $/ \mathrm{HBr} / \mathrm{H}_{2} \mathrm{O}$ system using dynamic light scattering (DLS) and electronic absorption spectra (EAS) were studied. The formation of nano- and micro-sized complexes with hydrodynamic radius $0.001-2.8 \mu \mathrm{m}$ within the temperature interval $293-333 \mathrm{~K}$ and as a function of concentration of hydrobromic acid and $\mathrm{K}_{2} \mathrm{ReBr}_{6} / \mathrm{p}$-aminobenzoic acid ratio are shown.

\section{Keywords}

Potassium Hexabromorhenate(IV); p-aminobenzoic acid; Dynamic Light Scattering; Particle Size Distribution, Electron Absorption Spectra

\section{Discipline And Sub-Disciplines}

Inorganic chemistry

\section{TYPE (METHOD/APPROACH)}

Experimental and spectral analys is

\section{Council for Innovative Research}

Peer Review Research Publishing System

Journal: Journal of Advances in Chemistry

Vol. 11, No. 3

editorjaconline@gmail.com

www.cirjac.com 


\section{INTRODUCTION}

Amino acids are the most important bioligands, they are part of the peptides and proteins. The latter play a major role in all life processes. Amino acids (AA) are considered as model ligands in the evaluation and prediction of interactions of the "metal-protein." Therefore, the development of new methods for the synthesis of complex compounds with the AA various metal ions, the establishment of specific types of ligands in the coordination compounds and their influence on the chemical nature of the metal and ligand study of their structure and properties are the contribution of both the fundamental knowledge of the chemistry of complex compounds and in related to the regulation of biological processes by metal ions. New data on the nature of the coordination of AA can improve the accuracy of predictions about the structure of the compounds studied yet and provide additional opportunities to improve techniques of directed synthes is of complexes of a given composition and structure [1-3].

The purpose of the article is to study the interaction of $K_{2} \operatorname{ReBr}_{6}$ salt with $p$-aminobenzoic acid ( $p$ - $A B A$ ) in hydrobromic acid medium and the effect of hydrobromic acid concentration on the complexation of $p-A_{B} A$ with $K_{2} R_{e B r}$ based on dynamic light scattering (DLS) and electronic absorption spectroscopy (EAS) in the UV a nd visible region.

\section{EXPERIMENTAL}

The used reagents: $\mathrm{HBr}$ acid, grade " Pure ", the manufacturer ReaChem., Russia, p-aminobenzoic acid, grade "Chemically pure", the manufacturer ReaChem., Russia , $\mathrm{KReO}_{4}$, grade "Chemically pure" , the manufacturer ReaChem., Russia, distilled water. $\mathrm{K}_{2} \mathrm{ReBr}_{6}$ obtained by a known method described in [K.B.Lebedev.Rhenium, Second Edition, State Sci.-Technical Publ. House , M. , 1963.208 p. (in Russian)], by reduction of potassium perrhenate $\mathrm{KReO}_{4}$ with excess amount of potassium iodide $(\mathrm{KJ})$ in the medium $7 \mathrm{M} \mathrm{HBr}$ hydrobromic acid :

$$
2 \mathrm{KReO}_{4}+6 \mathrm{KJ}+16 \mathrm{HBr} \rightarrow 2 \mathrm{~K}_{2} \mathrm{ReBr}_{6}+4 \mathrm{KBr}+3 \mathrm{I}_{2}+8 \mathrm{H}_{2} \mathrm{O}
$$

Then obtained solution was allowed to air. A few hours later well formed $\mathrm{K}_{2} \mathrm{ReBr}_{6}$ crystals of dark red color are precipitated. In this reaction $\mathrm{Re}^{7+}$ reduced to $\mathrm{Re}^{4+}$.

Preparation of complexes. $\mathrm{K}_{2} \mathrm{ReBr}_{6}$ complexes with $\mathrm{p}$ - $\mathrm{ABA}$ were obtained at a ratio mol per mol (1:1, 1:2, 1:4, 1:8, $1: 32)$ in $\mathrm{HBr}$ acid medium. $\mathrm{K}_{2} \mathrm{ReBr}_{6}$ powder in an amount of 0.744 grams was mixed well in a mortar $p$-ABA powder in an amount of 0.137 grams with the addition of 2-3 drops of $\mathrm{HBr}$ acid and heated at $45 \mathrm{C}$ for $30 \mathrm{~min}$. So, there was prepared $\mathrm{K}_{2} \mathrm{ReBr}_{6}$ with $\mathrm{p}$ - ABA (1:1). By the same way the other complexes were obtained. Then, before the DLS and ESP measurements the obtained complexes were transferred to a desiccator. Also before the DLS and EAS measurements solutions with the different concentration of these complexes were prepared. $10 \mathrm{mg}$ of each complex dissolved in $10 \mathrm{ml}$ of $\mathrm{HBr}$ acid solution and before the each next measurement the solution in cuvette was twice diluted. DLS measurements were carried out and EAS standard for spectrophotometric measurements and DLS with the same cuvette with the width of $1 \mathrm{~cm}$. Spectrophotometric measurements were made with a UV/VIS spectrophotometer. Linear sizes of the complexes formed in solution, their size distribution were studied by dynamic light scattering method using an apparatus LB-550, Horiba. The essence of the method is to measure the time-dependent fluctuations in the intensity of the scattered light from the particles that are in a random Brownian motion in the liquid phase. In liquids with suspended fine particles of random Brownian motion of dispersed particles causes fluctuations in their local concentration. In turn, these fluctuations lead to local inhomogeneities of the refractive index of the medium and light is scattered by these irregularities. The fluctuations of the scattered light intensity fluctuations correspond to the local concentration of the dispersed particles and the diffusion coefficient is uniquely associated with the radius of the particle [4-6]. For spherical particles can be used the Stokes-Einstein formula: $D=k_{\mathrm{B}} T / 6 \pi \eta R$, where $\mathrm{k}_{\mathrm{B}}$ - Boltzmann constant, $\mathrm{T}$ - absolute temperature, and $\mathrm{\eta}$ viscosity of the solution in which particles with the radius $\mathrm{R}$ are suspended. Used analyzer allows to explore the processes of complex formation in the temperature range 278-343 $\mathrm{K}$ and particles diameter range 0,001-6 $\mu \mathrm{m}$. The device provides automatic calculation of the backscattering by the Mie theory for spherical particles and irregular particles (needle-like) shape. Correct measurement results when analyzing the particle size distribution measurements confimed the standard for calibration of the system. Light source - $650 \mathrm{~nm}, 5 \mathrm{~mW}$, diode laser.

Electronic absortion spectra (EAS) detected using a spectrophotometer UV/VIS, Specord, Germany in the wavelength range 200-800nm in a temperature range of 293-353 K. Alfa FT-IR (Bruker, Germany) spectrometer is used for measuring the infrared spectra of complexes at room temperature in the range $350-7800 \mathrm{~cm}^{-1}$ (wavenumber accuracy: $\left.0.01 \mathrm{~cm}^{-1}\right)$.

\section{RESULTS AND DISCUSSION}

Figure 1, a,b shows the DLS spectra at $298 \mathrm{~K}$ of $\mathrm{K}_{2} \mathrm{ReBr}_{6} / \mathrm{p}-\mathrm{ABA}$ complexes in aqueous $\mathrm{HBr}(7 \mathrm{M})$ solutions with the ratio (mol to $\mathrm{mol}) 1: 1$ (a) and 1:4 (b). As shown from the fig. 1 at $298 \mathrm{~K}$ in the $\mathrm{HBr} /$ water solutions containing $\mathrm{K}_{2} \mathrm{ReBr}_{6}$ and $p$-ABA stabilized clusters with the sizes of hydrodynamic radius in the range $0.01-2,8 \mu \mathrm{m}$. The DLS picture changes over time after twice dilution of this solution with dis tilled water are shown in fig.2a-c. 


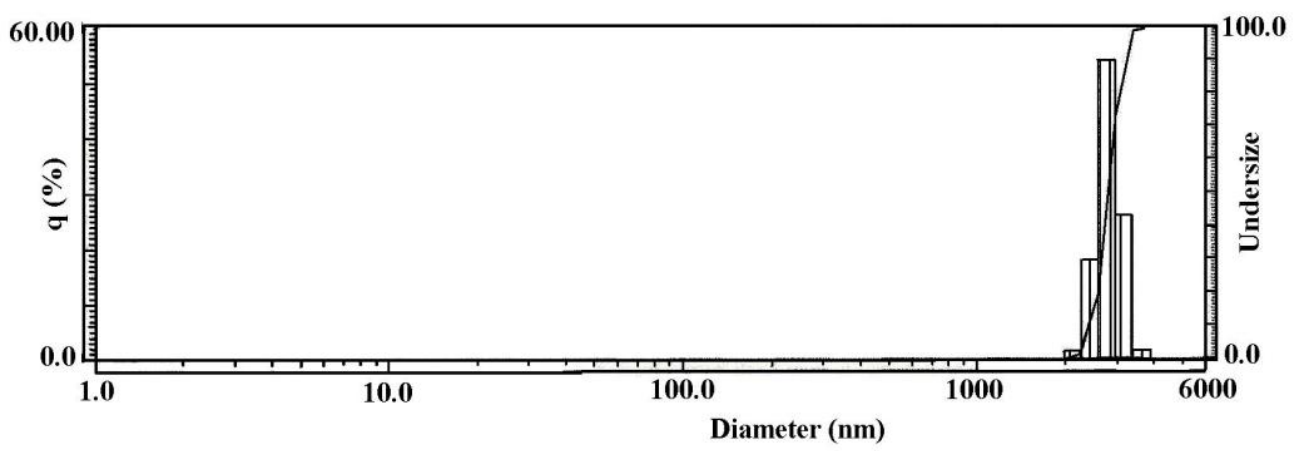

Figure 1,a.

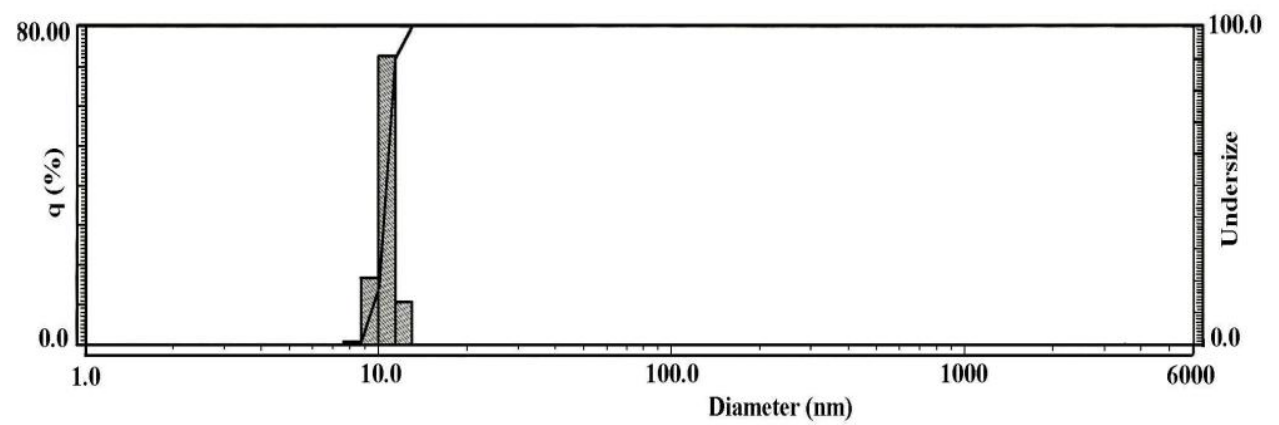

Figure 1,b.

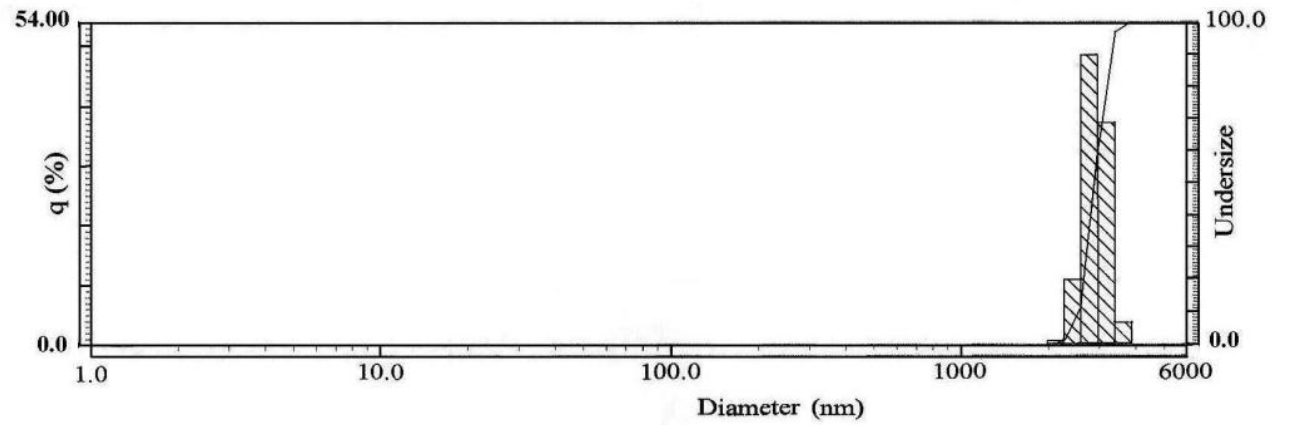

Figure 2,a.

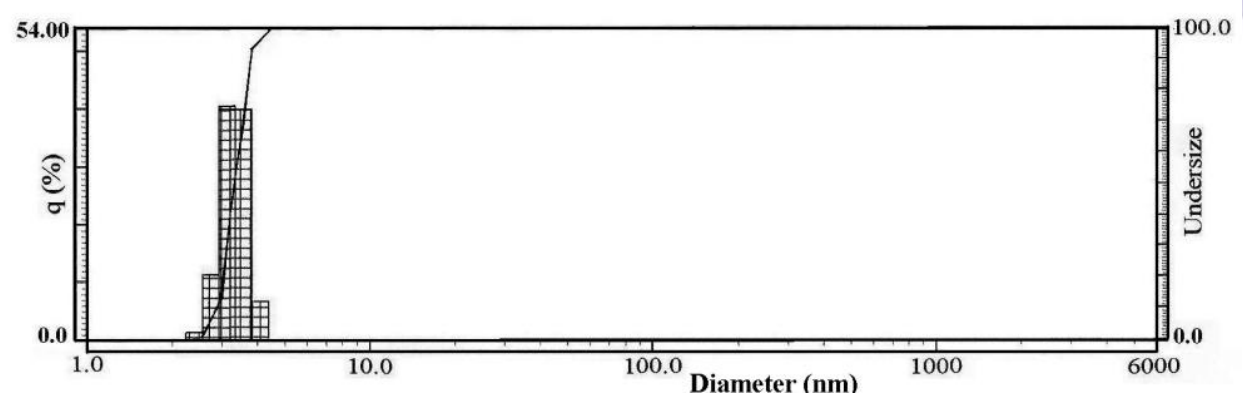

Figure 2,b 


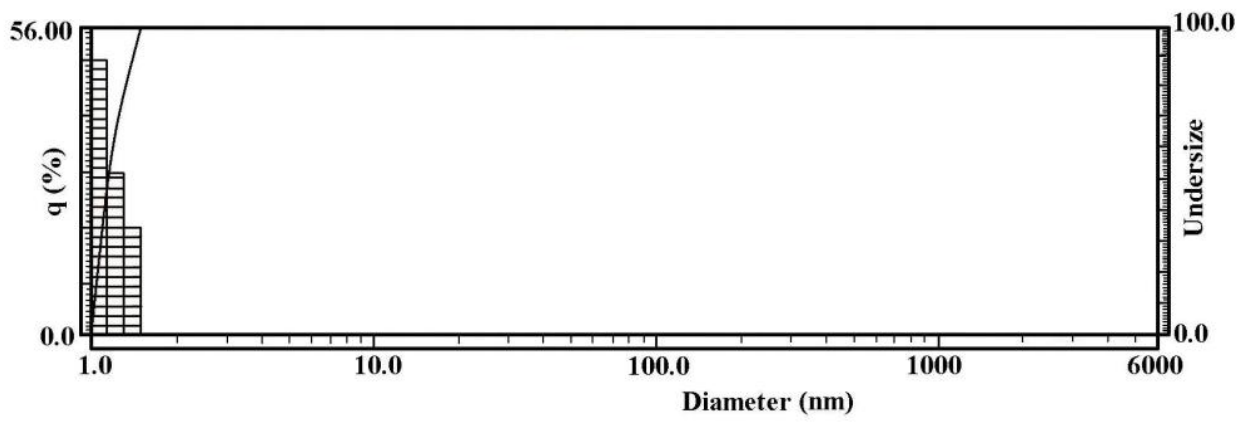

Figure 2,c.

Electronic absorption spectra of $\mathrm{K}_{2} \mathrm{ReBr}_{6}$ and products of its interaction with $\mathrm{p}$-aminobenzoic acid in solutions of $\mathrm{HBr}$ found a wide range of absorption bands between 200-800nm (fig 3,4).

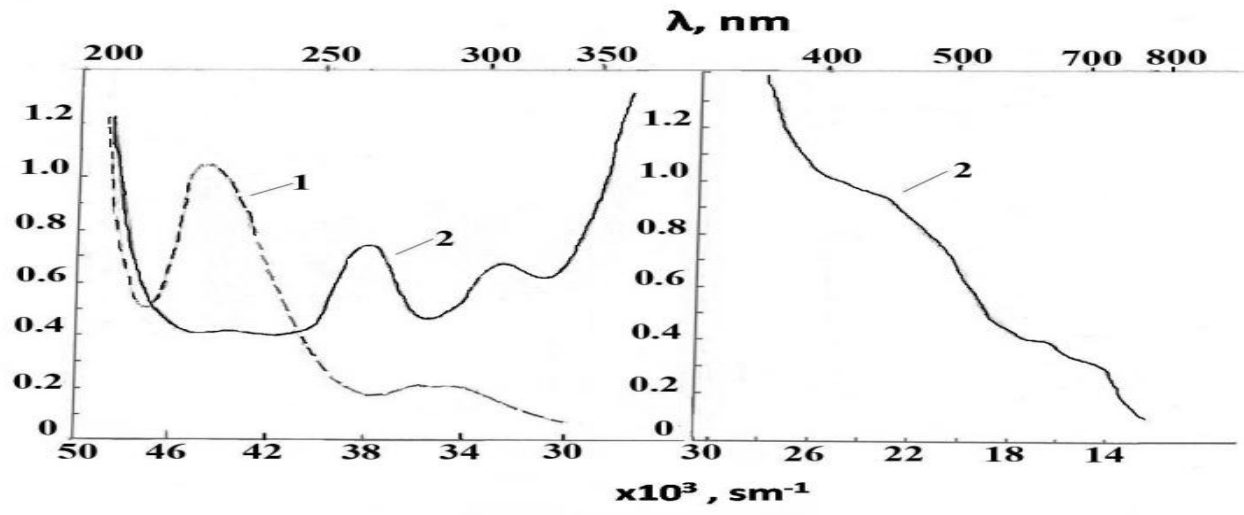

Figure 3.

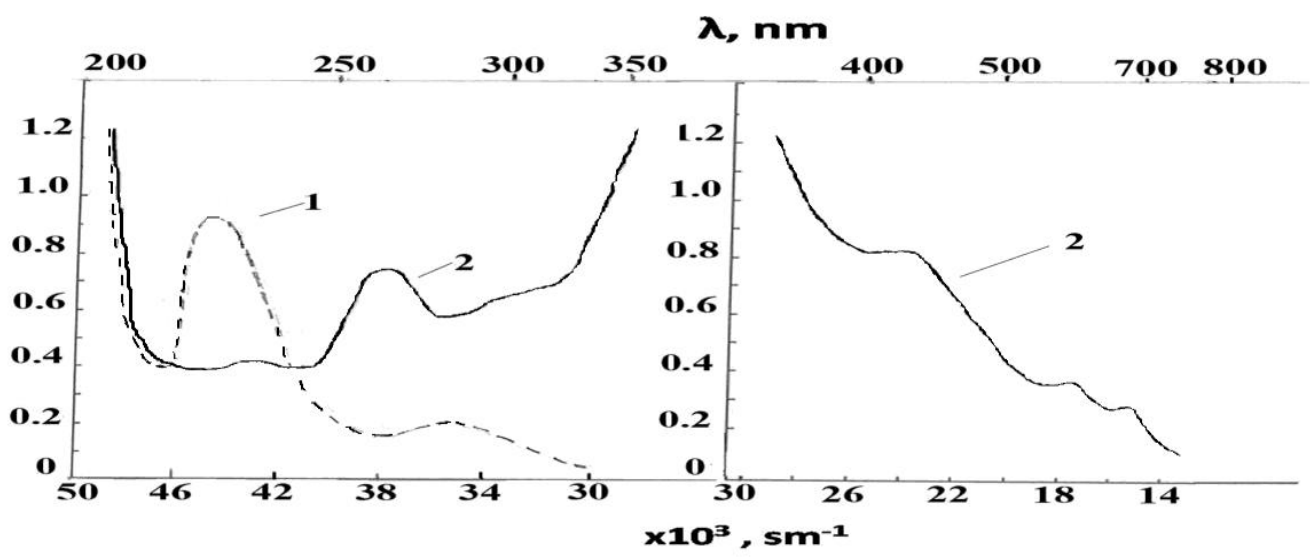

Figure 4.

The spectra marked as $1 \mathrm{in}$ fig. 3 and 4 belong to $\mathrm{HBr}$ solutions of $\mathrm{p}-\mathrm{ABA}$. The spectra marked as 2 belong to $\mathrm{HBr}$ solutions of $\mathrm{K}_{2} \mathrm{ReBr}_{6} / \mathrm{p}-\mathrm{ABA}$ complex with the ratio $(\mathrm{mol} / \mathrm{mol})$ : amino acid / rhenium salt = 1:1 before dilution (fig.3) and after dissolution with $7 \mathrm{M} \mathrm{HBr}$ acid of precipitate formed in diluted solution (fig.4). These spectra are typical for Re ${ }^{4+}$ complexes with chromophore $\left[\mathrm{ReBr}_{6}\right]^{2-}$, and $\mathrm{Re}^{5+}$ with chromophore $\left[\mathrm{ReOBr}_{5}\right]^{2-}$ with octahedral structure of the local environment of the rhenium ion $[7,8]$. Note that these spectra are obtained by dissolution of $\mathrm{ReO}_{2}$ in concentrated $\mathrm{HBr}$ in air, the detected spectra in the wavelength range $240-800 \mathrm{~nm}$ in this case are likely attributed to pentavalent oksobromid rhenium complex $\left[\mathrm{ReOBr}_{5}\right]^{2-}$. Noticeable changes appear in the range of absorption band at $420 \mathrm{~nm}$ when $\mathrm{ReO}_{2} \mathrm{powder}$ 
dissolved in hydrobromic acid at a concentration of less than $7 \mathrm{M}$, that probably due to the formation of hydrated oksobromide rhenium (V) complexes.

Thus, the presented results of this study show the complicated nature of complex formation in the system $\mathrm{K}_{2} \mathrm{ReBr}_{6} / \mathrm{p}-\mathrm{ABA} / \mathrm{HBr}$ as a function of $\mathrm{HBr}$ acid concentration. The formation and coexistence of nano- and micro-sized complexes with a hydrodynamic radius in the range of 0.001-2.8 microns and a different composition in these solutions are due to their dependence on the concentration of hydrobromic acid.

Role of $\mathrm{HBr}$ acid concentration. The concentration of hydrobromic acid significantly affects on complexation of $\mathrm{K}_{2} \mathrm{ReBr}_{6}$ with $\mathrm{p}-\mathrm{ABA}$. At lower concentrations of $\mathrm{HBr}$ acid $4 \mathrm{~mol} / \mathrm{l}(4 \mathrm{M} \mathrm{HBr})$ we have the gradual hydrolys is of the obtained complex, i.e. the replacing of $\mathrm{Br}$-ions by hydroxyl groups which is accompanied in further with the destruction of the complex obtained by the scheme:

$$
[\mathrm{p}-\mathrm{ABAH}]_{2}\left[\mathrm{ReBr}_{6}\right]+\mathrm{HOH} \rightarrow[\mathrm{p}-\mathrm{ABAH}]_{2}\left[\mathrm{ReBr}_{5}(\mathrm{OH})\right] \rightarrow \ldots \downarrow \operatorname{ReO}_{2}
$$

Visually the precipitation of $\mathrm{ReO}_{2}$ as a dark blue, almost black powder is observed. Note that the $\mathrm{HBr}$ acid in the reaction plays the role of a protonating agent of $\mathrm{p}$-aminobenzoic acid according to the scheme:

$$
\mathrm{HCOOC}_{6} \mathrm{H}_{4} \mathrm{NH}_{2}+\mathrm{HBr} \rightarrow \mathrm{HCOOC}_{6} \mathrm{H}_{4} \mathrm{NH}_{3}{ }^{+} \mathrm{Br}
$$

The obtained "onium" ion of p-amino benzoic acid is included in the outer sphere of the complex. The reaction proceeds with a reduction of $\mathrm{Re}^{6+}$ to $\mathrm{Re}^{4+}$ ions, but with the conservation of the number of bromide ions in the inner sphere $\left[\mathrm{ReBr}_{6}\right]^{2-}$.

$$
\mathrm{K}_{2} \mathrm{ReBr}_{6}+\mathrm{HCOOC}_{6} \mathrm{H}_{4} \mathrm{NH}_{2}+2 \mathrm{HBr} \rightarrow\left[\mathrm{HCOOC}_{6} \mathrm{H}_{4} \mathrm{NH}_{3}{ }^{+}\right]_{2}\left[\mathrm{ReBr}_{6}\right]^{2-}+2 \mathrm{KBr}
$$

The resulting complex is characterized by IR spectra. A characteristic absomtion band of carboxyl groups in the above complex appears at $1725 \mathrm{~cm}^{-1}$. The free ligand in the IR spectra of this band appears at $1620 \mathrm{~cm}^{-1}$. This indicates that in the resulting complex the carboxyl group is not involved in complexation directly through this group.

\section{CONCLUSION}

The used technique and their experimental possibilities allow to evaluate the linear sizes of the particles in the system $\mathrm{K}_{2} \mathrm{ReBr}_{6} / \mathrm{p}$-aminobenzoic acid/ $/ \mathrm{HBr} / \mathrm{H} 2 \mathrm{O}$ and to record electronic state for this solution practically in the same conditions of measurements. How to correlate DLS and EAS measurements? It is obviously the particle size and electronic state characteristics of the system are linked. Electronic state of a particle depends of course on the size of the particle. It also depends on the particle shape, composition, etc.. Are the observed DLS and EAS spectra belong to the same structure? The answer to this question requires additional theoretical and experimental researches. The aim of this work primarily is to present experimental results that may be further examined in this direction. Conceming of this case we have very interesting perspective to combine electronic and dimensional characteristics of supramolecular structures, clusters of large molecules, etc. For the same solution in the same cuvette with a thickness of $1 \mathrm{~cm}$ were recorded as DLS and EAS spectra. By DLS we obtain the linear dimensions of complex, its adducts, clusters, aggregates, if they are existence in the solution and their sizes are in the range of $1 \mathrm{~nm}$ to 6 microns. In EAS we were recorded electronic transitions for solutions of these complexes. As can be seen electronic and dynamic light spectra are very sensitive to any changes in the system based on the $p-A B A$ and Re salt.

\section{Figure captions.}

Figure 1, a, b. DLS picture at $298 \mathrm{~K}$ when $\mathrm{HBr}$ solutions of $\mathrm{K}_{2} \mathrm{ReBr}_{6}$ aminobenzoic acid complexes with a ratio $(\mathrm{mol} / \mathrm{mol})$ of the amino acid / salt of rhenium: a) $1: 1, \mathrm{~b}) 1: 4$.

Figure 2, a-c. DLS picture of $1 \mathrm{mg} \mathrm{K} \mathrm{KeBr}_{6} /$ aminobenzoic acid complexes with ratio (mol/mol): amino acid / rhenium salt $=1: 1 \mathrm{in} 10 \mathrm{ml}$ of $7 \mathrm{M} \mathrm{HBr}$ solution at $298 \mathrm{~K}$ after twice dilution with distilled water over the time: a) 2 , b) 20 , c) $30 \mathrm{~min}$.

Figure 3. EAS spectra of : 1-p-ABA $\mathrm{HBr}$ and $2-\mathrm{K}_{2} \mathrm{ReBr}_{6} /$ aminobenzoic acid / $\mathrm{HBr}$ solutions with ratio (mol/mol): amino acid / rhenium salt $=1: 1$ at $298 \mathrm{~K}$.

Figure 4. EAS spectra of dissolved in powder $\mathrm{ReO}_{2}$ in $7 \mathrm{M} \mathrm{HBr}$ acid precipitated from the twice diluted with distilled water of the initial $\mathrm{HBr}$ solutions of: $1-\mathrm{p}-\mathrm{ABA}$ and $2-\mathrm{K}_{2} \mathrm{ReBr}_{6} /$ aminobenzoic acid mix with ratio (mol/mol): amino acid $/$ rhenium salt $=1: 1$ at $298 \mathrm{~K}$.

\section{REFERENCES}

1. Panyushkin V.T., Bukov N.N., Bolotin S.N., Volinkin V.A. The coordination chemistry of natural amino acids. Moscow: Nauka, (Russia). 2007. p.247.

2. Golovniov N.N., Novikova G.V. and others. Synthesis of compounds of elements with d-amino acids //Herald KSU. Natural Sciences, Krasnoyarsk State University,Russia, 2006, № 2 - p.38-44.

3. Kerimova U.A., Osmanov N.S., Akhmedov M.M., Khudaverdiyev R.A, Abbasov J.A "Synthesis and properties of complexes of rhenium (IV) with aminoacetic acid. "// Chemical problems (Azerbaijan), 2008, №2, p.277

4. Berne, B.J.; Pecora, R. Dynamic Light Scattering with applications to Chemistry, Biochemistry and Physics, Courier Dover Publications, 2000, 377 ps. 
5. Fröba A.P., Leipertz A. Diffusion Measurements in Fluids by Dynamic Light Scattering// Diffusion Fundamentals, 2005, 2, $63.1-63.25$

6. Dynamic Light Scattering Particle Size Analyzer LB-550, Instruction Manual, HORIBA, March 2009, 195 ps.

7. Rulfs C.L., Meyer R.J.. Rhenium(IV) Compounds: Synthesis aand Properties. J.Amer.Chem.Soc.,v.77, N17, pp. 45054507,1955

8. Lever A.B.P. Inorganic Electronic Spectroscopy (Second Edition), Elsevier Science Pullishers B.V.1984, 944 ps. 